\title{
HeAlth Effects And Pesticide Perception as DETERMINANTS OF PESTICIDE USE: EVIDENCE FROM BANGLADESH
}

\author{
Susmita Dasgupta* \\ Craig Meisner \\ Development Economics Research Group \\ The World Bank \\ Mainul Huq \\ Development Policy Group \\ Bangladesh
}

\begin{abstract}
In a recent survey of 820 Boro (winter rice), potato, bean, eggplant, cabbage, sugarcane and mango farmers in Bangladesh, over $47 \%$ of farmers were found to be overusing pesticides. With only $4 \%$ of farmers formally trained in pesticide use or handling, and over $87 \%$ openly admitting to using little or no protective measures while applying pesticides, overuse is potentially a very threatening problem to farmer health as well as the environment.

To model pesticide overuse, we used a 3-equation, trivariate probit framework with health effects and misperception of pesticide risk as endogenous dummy variables. Health effects (the $1^{\text {st }}$ equation) were found to be strictly a function of the amount of pesticides used in production, while misperception of pesticide risk (the $2^{\text {nd }}$ equation) was determined by health impairments from pesticides and the toxicity of chemicals used. Pesticide overuse (the $3^{\text {rd }}$ equation) was a significantly determined by variation in income, farm ownership, the toxicity of chemicals used, crop composition and geographical location.

The results highlight the necessity of policymakers to design effective and targeted outreach programs which deal specifically with pesticide risk, safe handling and averting behavior. Ideally, the approach would be participatory in nature to address key informational gaps, as well as increasing a farmers' awareness retention. The results also point to specific crops and locations experiencing a higher prevalence of overuse - bean and eggplant in general, and overall production in the districts of Chapainawabganj, Chittagong, Comilla, Jessore, Narshingdi, Rajshahi and Rangpur. Focusing efforts in these crop and geographical areas may have the most measurable effects on pesticide overuse.
\end{abstract}

World Bank Policy Research Working Paper 3776, November 2005

The Policy Research Working Paper Series disseminates the findings of work in progress to encourage the exchange of ideas about development issues. An objective of the series is to get the findings out quickly, even if the presentations are less than fully polished. The papers carry the names of the authors and should be cited accordingly. The findings, interpretations, and conclusions expressed in this paper are entirely those of the authors. They do not necessarily represent the view of the World Bank, its Executive Directors, or the countries they represent. Policy Research Working Papers are available online at http:/lecon.worldbank.org.

* - The authors' positions are, respectively, Senior Economist and Consultant, Development Research Group, World Bank (WB) and Consultant, Development Policy Group, Bangladesh. Financial support for this study has been provided by the World Bank's Development Research Administration.

Correspondence should be addressed to: Susmita Dasgupta, MC2-205, World Bank, 1818 H Street, NW, Washington, DC 20433, sdasgupta@,worldbank.org. 


\section{Introduction}

During the past three decades, indiscriminate use of chemical pesticides in agriculture has created serious health and environmental problems in many developing countries (World Resources, 1998-99). The World Health Organization (WHO) and the United Nations Environment Program estimate pesticide poisoning rates of 2-3 per minute, with approximately 20,000 workers dying from exposure every year, the majority in developing countries (WHO, 1990; Kishi et al., 1995; Pimental et al., 1992; Rosenstock et al., 1991). From an environmental perspective, chemically-polluted runoff from fields has contaminated surface and ground waters, damaged fisheries, destroyed freshwater ecosystems and created growing "dead zones" in ocean areas proximate to the mouths of rivers that drain agricultural regions (Pimental and Lehman, 1993; Tardiff, 1992). ${ }^{1}$

Many of these impacts are a direct result of the overuse and misuse of pesticides, often wildly deviating from recommended application procedures. Several recent studies investigating this behavior found that inadequate product labeling and farmers' lack of information often lead to widespread overuse or misuse of dangerous pesticides in developing countries (Huan et al., 2000; Dung and Dung, 1999; Dung et al., 1999). Anecdotal evidence also suggests that farmers use toxic chemicals extensively due to their reputation for speed and effectiveness; sometimes associating higher amounts with increased effectiveness.

The health and environmental hazards of pesticides can be partly avoided by education and the creation of incentives to curb the trend of overuse. However, a clear understanding of farmers' perception of risk and pesticide application behavior is necessary in the design of any policy intervention. Currently, systematic studies of the application of pesticides are scarce in developing countries. This paper is an attempt to close this research gap by providing quantitative estimates of pesticide overuse as well as

\footnotetext{
${ }^{1}$ In addition, what was initially deemed as localized pollution has now become a global problem, as toxic compounds from pesticides accumulate in oceanic food chains, and even in the tissues of land mammals in "pristine" polar regions (Blais et al., 1998).
} 
an analytical perspective of its determinants drawing on new survey data from Bangladesh.

We randomly selected and interviewed over 821 farmers across Bangladesh with structured questionnaires containing information on their input use \& yield; farmers' characteristics; knowledge of pesticides and sources of information, precautions and damage-averting behavior along with any associated health effects. From their responses, we developed a simultaneous three-equation model of farmers' overuse, risk perception and health effects of pesticides. Our analysis indicates that the toxicity of pesticides, crop composition, location and other socio-demographic factors determine the incidence of overuse. To the best of our knowledge, such in-depth studies of overuse of pesticides are non-existent in the literature, especially in the context of developing countries. The current study did not permit us to investigate issues such as the use of faulty equipment leading to overuse, mis-labeling or content switching, nor the role of pesticide subsidies in pesticide overuse. These issues remain as important research issues that should be the focus of further studies into the farmers' behavior of pesticide overuse.

The remainder of the paper is organized as follows. In Section 2 we describe the trend of pesticide use and the associated problems in Bangladesh. In Section 3 we present the survey, and in Section 4 we describe the dataset. The models, along with our econometric findings, are documented in Section 5. In Section 6 we conclude and offer some implications of our findings.

\section{Pesticide Use in Bangladesh at a Glance}

As in many developing countries, Bangladesh ${ }^{2}$ has promoted the use of pesticides to expand agricultural land and increase output per acre. Promotional activities have included extension services and significant subsidies (Rasul and Thapa, 2003; Hossain 1988). As a consequence of this expansive policy, pesticide use has more than doubled since 1992, rising from 7,350 metric tons to 16,200 metric tons in 2001 (See Figure 1). A

\footnotetext{
${ }^{2}$ Approximately $84 \%$ of Bangladesh's people are directly or indirectly dependent on agriculture for their livelihood, and agriculture contributes about $24 \%$ of gross domestic product (Bangladesh Bureau of Statistics, 2001).
} 
FAO analysis of pesticide composition revealed high shares of toxic chemicals (for example, carbamates and organophosphates in insecticides, and dithiocarbamates and inorganics in fungicides) which have been known to cause cancer, genetic damage, fetal damage, and severe allergic responses in exposed populations (Zahm, Ward and Blair, 1997).

Figure 1: Trends in Pesticide Use, 1992-2001

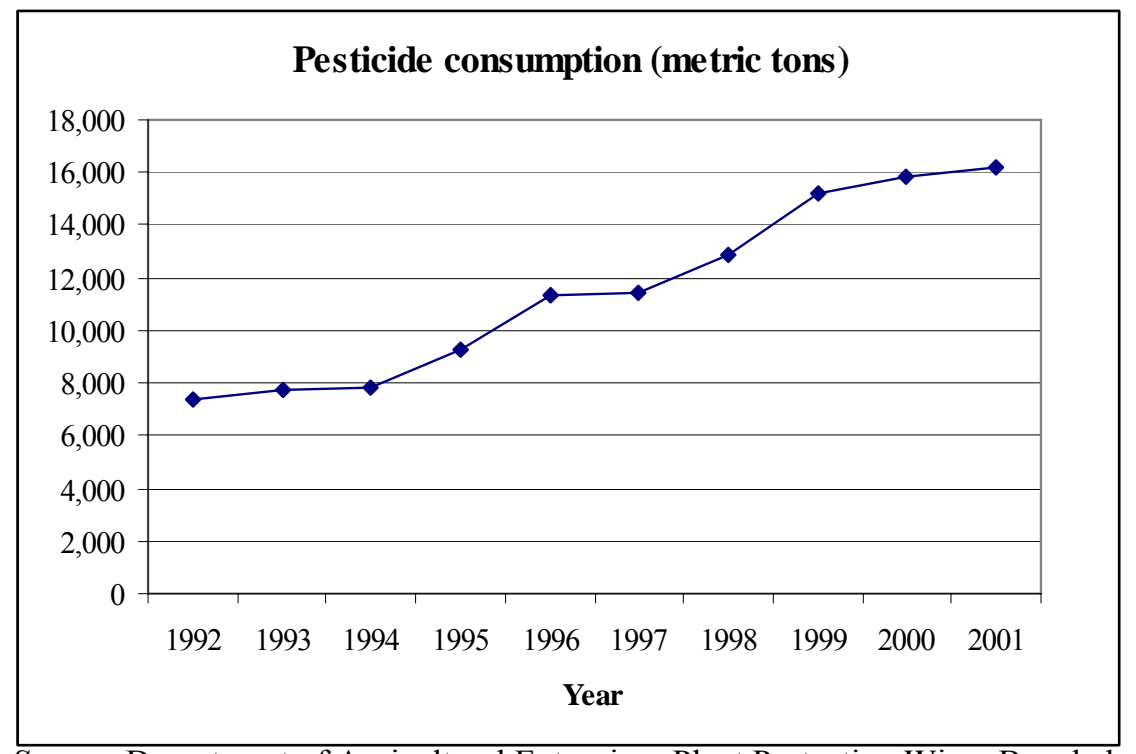

Source: Department of Agricultural Extension, Plant Protection Wing, Bangladesh

Many pesticides used in Bangladesh are also banned or restricted under international agreements (Meisner, 2004; NOVIB, 1993; SOS-arsenic.net, 2004, SUNS, 1998). Pesticide suppliers in Bangladesh even continue to sell the 12 particularly controversial pesticides known by activists campaigning worldwide as the "dirty dozen" (SUNS, 1998; SOS-arsenic.net, 2004). In addition, substantial anecdotal evidence suggests that users' lack of information have led to widespread overuse or misuse of pesticides. As a result, pesticide poisonings and ecological damage have become common in Bangladesh (Ramaswamy, 1992).

\section{Survey Data}

The research reported in this paper is based on a large survey of Bangladeshi farmers, carried out by the World Bank in the summer of 2003. We used structured questionnaires to collect information on pesticide use and practices, risk perceptions, knowledge, 
precautions and damage-averting behavior, and health effects from 821 farmers, randomly selected. ${ }^{3}$ The survey, by design, focused on major pesticide intensive crops such as Boro (winter rice), potato, bean, eggplant, cabbage, sugarcane and mango. To provide greater depth, we also interviewed 68 randomly-selected farmers who currently use Integrated Pest Management (IPM). The sample was also geographically stratified among 11 districts of Bangladesh as: Bogra, Chapainawabganj, Rajshahi, and Rangpur districts in the Rajshahi division (Northwest); Chittagong and Comilla in the Chittagong division (East); Jessore in the Khulna division (West); and Kishoreganj, Munshiganj, Narsingdi, and Mymensingh in the Dhaka division (North - see Figure 2). Table 1 displays the regional distribution of farmers in our sample.

\section{Table 1: Regional Distribution of Survey Respondents}

\begin{tabular}{lcc}
\hline District & No. of Farmers & Percent \\
\hline Bogra & 39 & 4.8 \\
Chapainawabganj & 8 & 1.0 \\
Chittagong & 76 & 9.3 \\
Comilla & 80 & 9.7 \\
Jessore & 195 & 23.8 \\
Kishoreganj & 41 & 5.0 \\
Munshiganj & 27 & 3.3 \\
Narsingdi & 86 & 10.5 \\
Rajshahi & 158 & 19.2 \\
Rangpur & 36 & 4.4 \\
Mymensingh & 75 & 9.1 \\
\hline Total & 821 & 100.0 \\
\hline
\end{tabular}

To minimize reporting bias, the survey was implemented under the agreement that the team would not reveal the identity of the farms surveyed or the respondents who participated.

\footnotetext{
${ }^{3}$ The survey was designed and supervised by the World Bank team, and conducted by the Development Policy Group in Bangladesh.
} 
Figure 2: Survey Districts in Bangladesh.

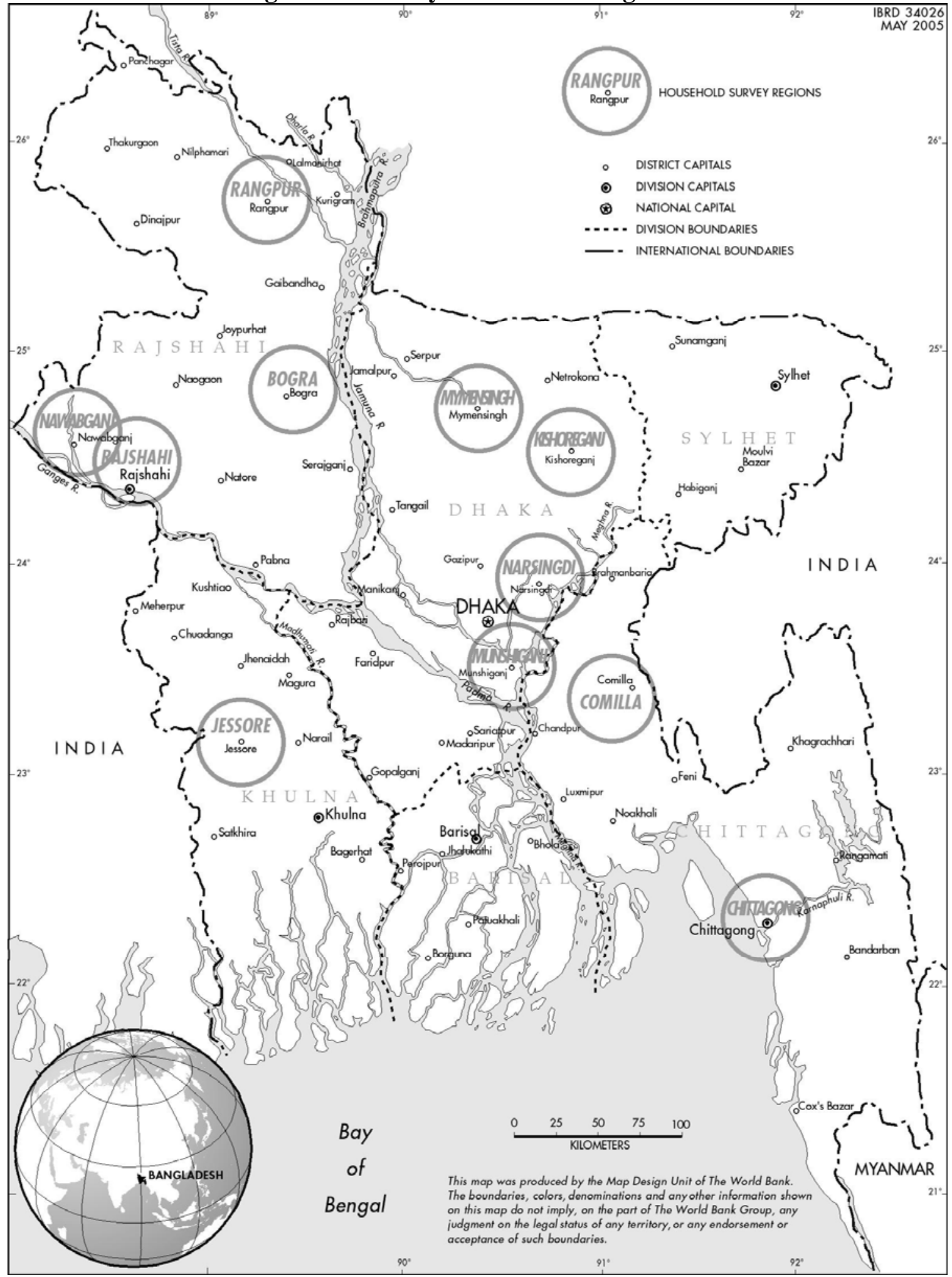




\section{Data}

\section{Farmer characteristics}

Of the 821 farmers surveyed, all were male, averaging 35 years in age (range $16-$ 75), and half with at least primary education. $80 \%$ of the farmers own their farms with the average farm size of 1.14 acres. Each farmer grows rice and a variety of vegetables. The average annual income reported was BGD Taka 97,057 ( $\$ 1$ USD=63.2 Taka) (\$1,536 USD).

\section{Pesticides in Use}

In terms of the number of pesticides applied, there were a total of 161 formulations (using 50 different active ingredients). Classifying these by the WHO risk classification system, on average, 19\% were extremely hazardous (WHO class I), 51\% very hazardous (WHO class II), 10\% moderately hazardous (WHO class III) and 20\% were low risk (class U). The number of applications per season varied between 1 and 16, with an average of 4 applications.

\section{Pesticide Overuse}

Overuse of pesticides, for this research, was calculated as the amount by which the farmer exceeded the recommended dose indicated on the label of the pesticide container. Recommended dosages were also cross-referenced with those conventionally followed in developed countries (e.g. in particular, with those stated in The e-Pesticide Manual, British Crop Protection Council (editor: Tomlin, 2003) and the Extension Toxicology Network, 2004). If the farmer used less than the recommended dose, overuse was coded as zero. This calculation was performed for all chemicals used in each application, then summed across individuals. ${ }^{4}$ Approximately $47 \%$ of the sample was found to have overused pesticides, to some extent, and with an average overuse rate of $3.4 \mathrm{~kg}$ per growing season. The overuse amount was then set to 1 to facilitate probit model estimation.

\footnotetext{
${ }^{4}$ Overuse per WHO class could also be conducted, however, our exercise accounts for toxicity through WHO class proportions in the final regression.
} 


\section{Misperception of risk}

Misperception of a pesticides' toxicity is also of interest as this may influence the dose decision by farmers. A priori, we expect farmers would be less likely to use a pesticide that is relatively higher in toxicity, if an equivalently effective and less toxic pesticide is available to the farmer. Studies have shown that farmers tend to rank pesticides more generally, with less distinction at the higher levels of toxicity (Warburton, Palis and Pingali, 1995). During the interview, farmers were asked to rank each chemical they applied in terms of its relative toxicity. Four categories were presented and scaled according to the corresponding WHO class description ( $1=$ slightly hazardous (WHO class III); 2=moderately hazardous (WHO class II); 3=highly hazardous (WHO class Ib); and 4=extremely hazardous (WHO class Ia). Misperception was then defined as any deviation from the true toxicity class. ${ }^{5}$ This procedure was repeated for each chemical and summed by farmer and toxicity class (four of them). Misperception was then set $=1$ if the farmer was incorrect at least $50 \%$ of the time, 0 otherwise. By coding in this manner, on average, over $48 \%$ of farmers incorrectly classified at least one of the pesticides they are using, and over 34\% were incorrect at least $50 \%$ of the time.

\section{Training and averting behavior}

As farmers mix and spray pesticides, they are naturally exposed to the toxicity of the chemicals. Exposure to pesticides can lead to an array of health effects, depending on the pesticide's toxicity and the dose absorbed by the body. ${ }^{6}$ However, the health effects of pesticide use can often be reduced significantly by averting behavior - wearing protective clothing (Cropper, 1994) and exercising precaution. The extent of averting behavior of a

\footnotetext{
${ }^{5}$ For example, if a farmer reported a 2 (class II), when in fact the chemical was a 3 (class Ib), this represented a deviation of 1 . If a farmer was more precautious, and reported a class higher than actual, this yielded a negative coding.

${ }^{6}$ For pesticides with high acute toxicity, exposure can produce intoxication symptoms within minutes or hours, and these acute effects run from mild headaches and flu like symptoms, to skin rashes, blurred vision, and other neurological disorders (World Resources, 1998-99). In addition, prolonged exposure to pesticides can cause many chronic health effects: cardiopulmonary problems, neurological and hematological symptoms, and adverse dermal effects (Davies, Freed, and Whittemore, 1982; Spear, 1991).
} 
farmer, in turn, depends on the perception of risk and training received on safe handling of pesticides. In our survey, only $4 \%$ farmers reported receiving basic training on the use of pesticides and safe handling ${ }^{7}$, while $87 \%$ openly admitted that they do not take any protective measures during the handling of pesticides.

\section{Health effects}

A detailed medical examination of sample farmers was beyond the scope of the study. Instead our analysis relied solely on self-assessed/ reported health effects, where farmers were questioned if they experienced any health impairment after mixing and spraying pesticides. ${ }^{8}$ Over $49 \%$ of farmers experienced at least one symptom, with the most commonly reported as neurological (headaches: $27 \%$, dizziness: $8 \%$ ), eye (irritation: 26\%), dermal (skin: 13\%), and gastrointestinal (vomiting: 9\%). The interviews further revealed that $26 \%$ of the respondents experienced multiple health effects, with an average of 3 and a maximum of 5. Upon asking sick farmers whether they believed that these symptoms were related to pesticide use, $82 \%$ believed this to be true. The health effects variable, "sick" was defined as whether a farmer experienced at least one symptom $(=1)$ or not $(=0)$.

\section{Determinants of Farmer's Pesticide Overuse}

\section{The model}

To model pesticide overuse, we used a trivariate probit framework with farmers' misperception of risk and health effects as endogenous dummy variables. The structure of the model follows a three-equation form where the estimation outcome of the first equation is used as a regressor in the second equation, and the second outcome in the third as follows:

\footnotetext{
${ }^{7}$ The primary sources of information for pesticide use and handling were: pesticide suppliers or companies (67.27\%), the Agricultural Ministry (19.09\%) and "personal knowledge" (10.91\%).

${ }^{8}$ Are self-reported health effects a credible measure? Detailed information for Bangladeshi farmers is virtually non-existent, however, medical tests of the farming population in other Asian countries may be indicative. Several clinical studies conducted on rice and vegetable farmers in Indonesia, Philippines, and Vietnam revealed $58 \%$ - 99\% of the farmers exposed to pesticides had at least one health effect (Xuyen et al., 1998; Kishi et al., 1995; Antle and Pingali, 1994; Rola and Pingali, 1993). This evidence suggests that the degree of upward bias, if at all in a self-assessment of health effects in Bangladesh may not be large.
} 


$$
\begin{aligned}
& y_{1 i}^{*}=\beta_{1} x_{1 i}+u_{1 i} \\
& y_{2 i}^{*}=\delta_{1} y_{1 i}+\delta_{2} z_{2 i}+u_{2 i} \\
& y_{3 i}^{*}=\delta_{3} y_{2 i}+\delta_{4} z_{3 i}+u_{3 i}
\end{aligned}
$$

where $y_{1 i}^{*}, y_{2 i}^{*}$ and $y_{3 i}^{*}$ are latent variables, and $y_{1 i}, y_{2 i}$ and $y_{3 i}$ are the observed dichotomous variables following the rule:

$$
\begin{cases}y_{k i}=1, & \text { if } y_{k i}^{*}>0 \\ y_{k i}=0, & \text { otherwise; } k=1,2,3\end{cases}
$$

where $x_{1 i}, z_{2 i}$, and $z_{3 i}$ are vectors of exogenous variables, $\beta_{1}, \delta_{2}$ and $\delta_{4}$ are parameter vectors and $\delta_{1}$ and $\delta_{3}$ are scalar parameters. The three covariate vectors, $x_{1 i}, z_{2 i}$, and $z_{3 i}$ are not restricted to containing the same variables of interest, as long as there exists at least one varying exogenous regressor in each equation in (1) (Wilde, 2000). The error terms are assumed to be independently and identically distributed as trivariate normal:

$$
\left(\begin{array}{l}
u_{1 i} \\
u_{2 i} \\
u_{3 i}
\end{array}\right) \sim I I D N\left(\left[\begin{array}{l}
0 \\
0 \\
0
\end{array}\right],\left[\begin{array}{ccc}
1 & \rho_{12} & \rho_{13} \\
\rho_{12} & 1 & \rho_{23} \\
\rho_{13} & \rho_{23} & 1
\end{array}\right]\right)
$$

where $\rho$ is the correlation between the unobservable explanatory variables, $u_{1 i}, u_{2 i}$, and $u_{3 i}$ of the three equations. In estimation, the coefficient of $\rho \neq 0$ can interpreted as the degree of endogeneity between $y_{1 i}$ and $u_{2 i}$ and $u_{3 i}$, since they are correlated; and likewise between $y_{2 i}$ and $u_{1 i}$ and $u_{3 i}$. The condition $\rho=0$ can be tested using a likelihood ratio (LR) test, which has been shown to be appropriate when testing for exogeneity in the simultaneous estimation of the bivariate probit model (Fabbri, Monfardini and Radice, 2004). A similar reasoning is used here in the trivariate case.

For the empirical model, we began by specifying the health effects equation as the first equation in (1) above, and simultaneously modeled farmer misperception as the second equation, with the overuse of pesticides as the third equation. According to the 
medical literature, the type and severity of pesticide poisoning depends on: (a) the toxicity of the pesticide, (b) the amount of pesticide involved in the exposure, (c) the route of exposure, and (d) the duration of exposure (Extension Toxicology Network, 2004). The health effects specification accounted for these factors, and following Antle and Pingali (1994), we also included age, nutritional status, income, the number of protections taken while handling pesticides and location. ${ }^{9}$ A farmers' perception of pesticides can be shaped by a variety of factors including the potential health implications, formal education and pesticide training (Warburton, Palis and Pingali, 1995). Thus in the second equation, farmers' misperception was specified as a function of the health effect, the degree of highly toxic use, age, education, training and location. In the third equation, overuse was specified as a function of farmer misperception, toxic use, age, income, education, farm size, ownership, training, practicing IPM and location. As crops differ substantially with respect to their vulnerability to pests, crop area proportions were also added to the overuse equation (see Appendix 1 for variable details).

SICKNESS $=f($ PESTAMT, PWHOIab, PWHOII, PWHOIII, NUTRTON, AGE, INCOME, NPROTECT, District Dummies)

MISPERCEPTION $=f$ (SICKNESS, AGE, EDUCATION, TRAIN, PWHOIab, PWHOII, PWHOIII, District Dummies)

OVERUSE $=f$ (MISPERCEPTION, AGE, FARMSIZE, OWNER, INCOME, EDUCATION, TRAIN, IPM Dummy, PWHOIab, PWHOII, PWHOIII, Crop proportions, District Dummies)

\section{Estimation results}

We estimated the three probit equations in (4) simultaneously, with the results presented in Table 2. The correlation coefficient between the error terms of the health effects and misperception equations is significantly different from zero at $1 \%$ level of significance, indicating that the unobserved variables influencing health effects are positively correlated with the unobserved characteristics affecting the misperception of pesticide risk. The other two correlation coefficients are not significant, suggesting that health and misperception are not endogenous in the overuse equation.

\footnotetext{
${ }^{9}$ Location controls were also included in the regression to take into account any possible pervasive contamination from neighboring pesticide use.
} 
Table 2: Triprobit results

\begin{tabular}{|c|c|c|c|}
\hline Variables & Health effects & Misperception & Overuse \\
\hline Pestamt & $\begin{array}{l}0.017 * * * \\
(3.21)\end{array}$ & & \\
\hline Sickness & & $\begin{array}{c}-1.032 * * * \\
(-4.28)\end{array}$ & \\
\hline Misperception & & & $\begin{array}{c}-0.491 \\
(-1.42)\end{array}$ \\
\hline Age & $\begin{array}{l}-0.006 \\
(-1.36)\end{array}$ & $\begin{array}{c}-0.003 \\
(-0.61)\end{array}$ & $\begin{array}{r}0.008^{*} \\
(1.65)\end{array}$ \\
\hline Nutrition & $\begin{array}{l}1.691 \\
(1.27)\end{array}$ & & \\
\hline Education & & $\begin{array}{l}0.034 \\
(0.82)\end{array}$ & $\begin{array}{l}0.061 \\
(1.21)\end{array}$ \\
\hline Farm size & & & $\begin{array}{l}0.022 \\
(0.51)\end{array}$ \\
\hline Owner & & & $\begin{array}{c}0.307 * * \\
(2.11)\end{array}$ \\
\hline Income & $\begin{array}{l}0.000001 * * * \\
(2.94)\end{array}$ & & $\begin{array}{l}0.000001 * * \\
(2.12)\end{array}$ \\
\hline Training & & $\begin{array}{c}-0.210 \\
(-0.88)\end{array}$ & $\begin{array}{c}-0.284 \\
(-1.00)\end{array}$ \\
\hline Nprotect & $\begin{array}{l}0.152 \\
(1.07)\end{array}$ & & \\
\hline Ipmd & & & $\begin{array}{l}0.152 \\
(0.73)\end{array}$ \\
\hline Pwholab & $\begin{array}{l}0.001 \\
(0.29)\end{array}$ & $\begin{array}{c}0.014 * * * \\
(6.23)\end{array}$ & $\begin{array}{c}-0.012 * * * \\
(-3.37)\end{array}$ \\
\hline PwholI & $\begin{array}{l}0.002 \\
(0.89)\end{array}$ & $\begin{array}{c}0.006 * * * \\
(3.18)\end{array}$ & $\begin{array}{r}0.004 * \\
(1.84)\end{array}$ \\
\hline PwholII & $\begin{array}{l}0.002 \\
(0.68)\end{array}$ & $\begin{array}{l}0.002 \\
(0.76)\end{array}$ & $\begin{array}{r}0.0004 \\
(0.13)\end{array}$ \\
\hline Bogra & $\begin{array}{l}0.948 * * * \\
(2.99)\end{array}$ & $\begin{array}{l}0.117 \\
(0.36)\end{array}$ & $\begin{array}{l}0.441 \\
(0.97)\end{array}$ \\
\hline Chapi & $\begin{array}{c}-0.385 \\
(-0.65)\end{array}$ & $\begin{array}{c}-0.054 \\
(-0.10)\end{array}$ & $\begin{array}{l}2.157 * * * \\
(3.01)\end{array}$ \\
\hline Chitta & $\begin{array}{l}0.242 \\
(0.96)\end{array}$ & $\begin{array}{c}-0.306 \\
(-1.19)\end{array}$ & $\begin{array}{l}1.995 * * * \\
(4.97)\end{array}$ \\
\hline Comilla & $\begin{array}{l}0.306 \\
(1.22)\end{array}$ & $\begin{array}{c}0.537 * * \\
(2.21)\end{array}$ & $\begin{array}{c}0.850 * * \\
(2.32)\end{array}$ \\
\hline Jessore & $\begin{array}{l}0.332 \\
(1.37)\end{array}$ & $\begin{array}{c}0.324 \\
(1.39)\end{array}$ & $\begin{array}{l}1.754 * * * \\
(4.98)\end{array}$ \\
\hline Munsh & $\begin{array}{c}-0.867 * * \\
(-2.13)\end{array}$ & $\begin{array}{r}-0.711 * \\
(-1.74)\end{array}$ & $\begin{array}{l}0.613 \\
(1.24)\end{array}$ \\
\hline Narsh & $\begin{array}{l}0.252 \\
(1.03)\end{array}$ & $\begin{array}{c}-0.200 \\
(-0.81)\end{array}$ & $\begin{array}{l}1.115 * * * \\
(3.11)\end{array}$ \\
\hline Rajshahi & $\begin{array}{l}0.148 \\
(0.62)\end{array}$ & $\begin{array}{c}-0.074 \\
(-0.31)\end{array}$ & $\begin{array}{l}2.054 * * * \\
(5.49)\end{array}$ \\
\hline Rangpur & $\begin{array}{c}-0.012 \\
(-0.04)\end{array}$ & $\begin{array}{l}0.187 \\
(0.64)\end{array}$ & $\begin{array}{r}0.774^{*} \\
(1.82)\end{array}$ \\
\hline Mymen & $\begin{array}{c}-0.033 \\
(-0.13)\end{array}$ & $\begin{array}{c}-0.376 \\
(-1.52)\end{array}$ & $\begin{array}{l}0.510 \\
(1.40)\end{array}$ \\
\hline Riceall & & & $\begin{array}{l}-1.613 * * * \\
(-5.44)\end{array}$ \\
\hline Potato & & & $\begin{array}{c}-1.051 * * \\
(-2.10)\end{array}$ \\
\hline Bean & & & $\begin{array}{c}-0.437 \\
(-0.82)\end{array}$ \\
\hline Eggplant & & & $\begin{array}{c}-0.596 \\
(-1.37)\end{array}$ \\
\hline Cabbage & & & $\begin{array}{r}-0.979 * \\
(-1.73)\end{array}$ \\
\hline Sugarcane & & & $\begin{array}{c}-2.239 * * * \\
(-4.38)\end{array}$ \\
\hline Mango & & & $\begin{array}{c}-2.368 * * * \\
(-4.61)\end{array}$ \\
\hline Constant & $-0.942 *$ & -0.443 & -0.822 \\
\hline
\end{tabular}




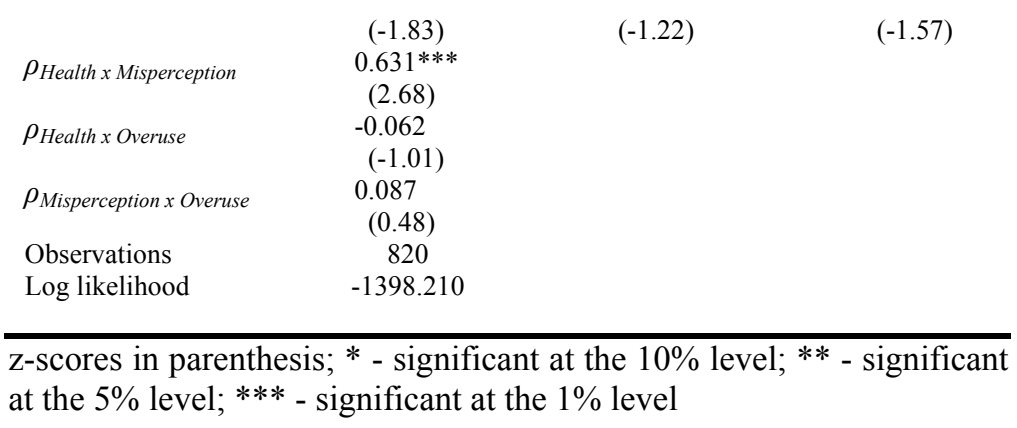

The first column of Table 2 presents the determinants of the health effects equation. Variables found to be significantly associated with the probability of a farmers' health impairment from pesticides are: the amount of pesticides applied and income. As expected, the probability of sickness increases significantly with greater use of pesticides. After controlling for the amount of pesticides, however, we did not find any statistical significance for the toxicity of pesticides. Income, although significant, has a perverse sign which we could not explain. ${ }^{10}$ Neither the age nor the nutritional status of the exposed had any significant effect on health. The number of protections taken by the farmer is also insignificant, however, low variation in the sample may be a possible explanation. District controls reveal that health impairments from pesticides are more likely in the Bogra district, and less likely in the district of Munshiganj.

The second column of Table 2 gives the determinants of the farmers' misperception of pesticide risk. The negative sign and significance (at the 1\% level) of health impairment clearly shows that the probability of misperception is lower with increases in health impairments. The positive and significant sign of two pesticide toxicity variables in the misperception equation reveal the incidence of misperception is higher for farmers with higher proportional use of WHO Ia \& Ib (extremely and highly hazardous) and WHO II (moderately hazardous) pesticides. This finding is analogous to that found by Warburton, Palis and Pingali (1995), where farmers tended to group WHO I and II pesticides as equally hazardous. It is worth noting that neither formal education nor training in use/ safe-handling had any effect on misperception. Once again, the very low (4\%) number of farmers actually trained in the sample may be the cause of its

\footnotetext{
${ }^{10}$ A t-test among income groups confirms the statistical difference in pesticide use. Note however that the marginal impact of changes in income is relatively small.
} 
insignificance. Among the districts, misperception appears to be most prevalent in Comilla, and significantly lower in Munshiganj.

The third column of Table 2 presents the determinants of the farmers' overuse of pesticides. Unfortunately, misperception did not yield the expected sign, however, it was not a significant determinant of overuse. ${ }^{11}$ Among the individual characteristics, income and ownership influence the propensity to overuse. For pesticide toxicity class, farmers with higher proportions of highly hazardous (WHO Ia \& Ib) pesticides are less likely to overuse, and farmers with higher proportions of moderately hazardous (WHO II) pesticides are more likely to overuse. Neither training in safe-handling nor use of IPM techniques has the expected effect. However, the application of pesticides revealed strong crop patterns. The incidence of overuse is less likely in the case of potato, rice, cabbage, sugarcane and mango as compared to eggplant and beans. In addition, even after controlling for individual circumstances and crops, we find a strong locational pattern. Overuse is more prevalent in the districts of Chapainawabganj, Chittagong, Comilla, Jessore, Narshingdi, Rajshahi and Rangpur than in Bogra, Mymensingh, Munshiganj and Kishoreganj (excluded).

\section{Summary and Conclusions}

Empirical evidence on pesticide application in developing countries is rather thin. Drawing on a new survey conducted in Bangladesh, this paper is an attempt to address this gap. In our survey, $47 \%$ of the farmers were found to have overused pesticides, with an average overuse rate of $3.4 \mathrm{~kg}$ per growing season. To model pesticide overuse, we used a trivariate probit framework with health effects and misperception of pesticide risk as endogenous dummy variables.

The results, to some extent, are consistent with our expectations. The variable found to be significantly associated with the probability of a farmers' health impairment from pesticides is: amount of pesticide applied. Among the determinants of probability of

\footnotetext{
${ }^{11}$ One possible explanation could be that with prolonged use over time, pesticide resistance necessitates greater use to achieve similar outcomes.
} 
misperception, health impairment from pesticides and toxicity of pesticides are significant. Among the determinants of overuse of pesticides, income, ownership, toxicity of pesticides, crop composition and location dominate.

When questioned, $49 \%$ of the farmers reported frequent health symptoms commonly associated with acute pesticide poisoning such as eye irritation, headaches, dizziness, vomiting and skin effects. Yet, $87 \%$ openly admitted that they do not take any protective measures during the handling of pesticides. The health effects of pesticide use can be reduced significantly by averting behavior - such as wearing gloves, eye glasses or a mask while handling pesticides and washing their hands after touching pesticides. There is an urgent need for active promotion of suitable averting behavior and hygienic practices among pesticide applicators/ farmers in Bangladesh.

Our analysis further indicated that there is dearth of formal training and information on use and safe handling in Bangladesh. Only $4 \%$ of the farmers surveyed reported receiving basic training on the use of pesticides and safe handling. This lack of training is reflected in the misperception of pesticide risks, where over $34 \%$ of respondents underclassified their pesticide hazard. This emphasizes the need for targeted outreach programs in agricultural communities, including farmer field schools and farmer participatory research. Participation by the farmer is a key element of any program, as he/she will retain more information and put this into practice (Heong, Escalada and Lazaro, 1995). The information content of training programs should include more specific information on the health hazards of pesticides and averting behavior. In the design of these training programs, it would be advisable to include farmers, to better reflect their needs and current informational gaps.

Our cross-section regression results suggest widespread pesticide overuse in the districts of Chapainawabganj, Chittagong, Comilla, Jessore, Narshingdi, Rajshahi and Rangpur. Our results also highlight that pesticide overuse in Bangladesh is heavily skewed towards a few selected vegetables - beans and eggplant. These findings suggest policies targeted towards these locations and crops may have measurable effects on 
pesticide overuse. Steps could include stricter enforcement of existing regulations, the promotion of integrated pest management programs, and further research on alternative pest control methods.

\section{References}

Antle, J. M. and P. L. Pingali 1994. Pesticides, Productivity, and Farmer Health: A Philippine Case Study. American Journal of Agricultural Economics, 76: 418-430.

Bangladesh Bureau of Statistics (BBS) 2001. Statistical Yearbook of Bangladesh, December 2003, Planning Division, Ministry of Planning, Government of the Peoples Republic of Bangladesh.

Blais, J. M., D. W. Schindler, D. C. G. Muir, L. E. Kimpe, D. B. Donald and B. Rosenberg 1998. Accumulation of Persistent Organochlorine Compounds in Mountains of Western Canada. Nature 395: 585-588.

Cropper, M. 1994. Economic and Health Consequences of Pesticide Use in Developing Country Agriculture: Discussion. American Journal of Agricultural Economics 76: 605-607.

Davies, V., H. Freed, and F. W. Whittemore 1982. An Agromedical Approach to Pesticide Management: Some Health and Environmental Considerations. Miami, Fla., USA: University of Miami School of Medicine in cooperation with the Agency for International Development (USAID) and Consortium of International Crop Protection.

Dung, N. H. and T. T. T. Dung 1999. Economic and Health Consequences of Pesticide Use in Paddy Production in the Mekong Delta, Vietnam. EEPSEA Research Report Series. Available at: http://www.eepsea.org/en/ev-8427-201-1-DO_TOPIC.html.

Dung, N. H., T. C. Thien, N. V. Hong, N. T. Loc, D. V. Minh, T. D. Thau, H. T. L. Nguyen, N. T. Phong and T. T. Son 1999. Impact of Agro-Chemical Use on Productivity and Health in Vietnam. EEPSEA Research Report Series. Available at: http://www.eepsea.org/en/ev-8427-201-1-DO_TOPIC.html.

Extension Toxicology Network (ECOTOXNET) 2004. Cholinesterase Inhibition. Toxicology Information Brief. Cornell University. Available at: http://pmep.cce.cornell.edu/profiles/extoxnet/TIB/cholinesterase.html

Fabbri, D., C. Monfardini and R. Radice 2004. Testing Exogeneity in the Bivariate Probit Model: Monte Carlo Evidence and an Application to Health Economics. Department Working Paper No. 514. Department of Economics, University of Bologna, Italy. 
Heong, K. L., M. M. Escalada and A. A. Lazaro 1995. Misuse of Pesticidas among Rice Farmers in Leyte, Philippines. In: Impact of Pesticides on Farmer Health and the Rice Environment. (P. L. Pingali and P. A. Roger, eds.). Kluwer Academic Publishers, Boston. pp. 97-108.

Hossain, M. 1988. Nature and Impact of the Green Revolution in Bangladesh. Research Report No. 67. International Food Policy Research Institute: Washington DC.

Huan, N. H., Le Van Thiet et al. 2000. Results of survey for confidence, attitude and practices in safe and effective use of pesticides. In Agro-Chemicals Report Vol. II, No. 1, January-March 2002. Available at: http://www.fadinap.org/nib/nib2002_1/jan2002pesticides1.PDF.

Kishi, M., N. Hirschhorn, M. Qjajadisastra, L. N. Satterlee, S. Strowman and R. Dilts 1995. Relationship of Pesticide Spraying to Signs and Symptoms in Indonesian Farmers. Scandinavian Journal of Work \& Environmental Health 21: 124-133.

Meisner, C. 2004. Report of Pesticide Hotspots in Bangladesh. Report to the Canadian International Development Agency (CIDA). Mimeo. World Bank: Washington DC.

NOVIB 1993. Pesticides Misuse in Bangladesh. The Pesticides News, No. 22, Dec. 1993. The Pesticides Trust. London: U.K.

Pimental, D., H. Acquay, M. Biltonen 1992. Environmental and Economic Costs of Pesticide Use. Bioscience 42, 750-60.

Pimental, D. and D. Lehman (ed.) 1993. The Pesticide Question: Environment, Economics, and Ethics. New York: Chapman and Hall.

Ramaswamy, S. 1992. Pest Control and Environment. Notes for discussion at a seminar on environment and agriculture. Agriculturalist Association of Bangladesh, Dhaka, p.19.

Rasul, G. and G. Thapa 2003. Sustainability Analysis of Ecological and Conventional Agricultural Systems in Bangladesh. World Development 31 (10): 1721-1741.

Rola, A. C. and P. L. Pingali 1993. Pesticides, Rice Productivity, and Farmer's Health: an economic assessment. International Rice Research Institute, World Resources Institute: Washington DC.

Rosenstock, L., M. Keifer, W. E. Daniell, R. McConnell, K. Claypoole 1991. Chronic Central Nervous System Effects of Acute Organophosphate Pesticide Intoxication. Lancet 338: 223-227.

Spear, R., 1991. Recognized and Possible Exposure to Pesticides. Handbook of Pesticide Toxicology. Vol. 1. General Principles. New York: Academic Press. 
SOS-Arsenic.net 2004. Agrochemicals: Imported Pollutants in Bangladesh. Available at: http://www.sos-arsenic.net/index.html.

SUNS 1998. Pesticide Overuse Takes Serious Turn in Bangladesh. Monday, Jan. 24, (Dhaka, Jan. 23 IPS/Tabibul Islam).

Tardiff, R. G. (ed.) 1992. Methods to Assess Adverse Effects of Pesticides on Non-Target Organisms. New York: John Wiley and Sons.

Tomlin, C. D. S. (ed.) 2003. The e-Pesticide Manual: A World Compendium, 13th Edition, Alton, Hampshire: British Crop Protection Council.

Warburton, H., F. G. Palis and P. L. Pingali 1995. Farmer Perceptions, Knowledge, and Pesticide Use Practices. In: Impact of Pesticides on Farmer Health and the Rice Environment. (P. L. Pingali and P. A. Roger, eds.). Kluwer Academic Publishers, Boston. pp. 59-95.

Wilde, J. 2000. Identification of Multiple Equation Probit Models with Endogenous Dummy Regressors. Economics Letters 69: 309-312.

World Health Organization (WHO) 1990. Public Health Impact of Pesticides Used in Agriculture, 1990. World Health Organization: New York, USA.

World Resources Institute, UNEP, UNDP, the World Bank 1998. Environmental Change and Human Health. World Resources 1998-99.

Xuyen, K., N. C. Hoi and P. Q. Trung 1998. Occupational Environment and Skin Diseases in Pesticide Exposed Subjects in some Tea Farms in Vietnam. Presentation given at the Third National Scientific Conference on Occupational Health, December 45, 1998. Hanoi.

Zahm, S. H., M. H. Ward and A. Blair 1997. Pesticides and Cancer. In: Occupational Medicine: State of the Art Reviews. Vol. 12: Pesticides (M. Keifer, ed.). Philadelphia: Hanley and Belfus, Inc., 269-289. 


\section{Appendix 1: Variable description}

\begin{tabular}{|c|c|}
\hline Variable & Description \\
\hline SICKNESS & $\begin{array}{l}=1 \text { if farmer reported any eye irritation, headache, dizziness, vomiting, diarrhea, } \\
\text { fever, convulsion, shortness of breath or skin irritation; }=0 \text { otherwise }\end{array}$ \\
\hline MISPERCEPTION & $=1$ if the farmer was incorrect at least $50 \%$ of the time; $=0$ otherwise \\
\hline OVERUSE & $\begin{aligned}=1 \text { if farmer reported overusing; } & =0 \text { otherwise } \\
& \text { Exposure }\end{aligned}$ \\
\hline PESTAMT & Pesticide amount used in production (kilograms) \\
\hline PWHOIab & $\begin{array}{l}\text { Proportion of pesticides applied and classified as WHO category Ia or Ib } \\
\text { (extremely or highly hazardous) }\end{array}$ \\
\hline PWHOII & $\begin{array}{l}\text { Proportion of pesticides applied and classified as WHO category II (moderately } \\
\text { hazardous) }\end{array}$ \\
\hline PWHOIII & $\begin{array}{l}\text { Proportion of pesticides applied and classified as WHO category III (slightly } \\
\text { hazardous) }\end{array}$ \\
\hline PWHOU & $\begin{array}{l}\text { Proportion of pesticides applied and classified as WHO category } \mathrm{U} \text { (unlikely to } \\
\text { present any acute hazard in normal use) (Dropped in estimation) } \\
\text { Socio-economic }\end{array}$ \\
\hline NUTRTON & Nutritional ratio of weight/height \\
\hline AGE & Age in years \\
\hline EDUCATION & $\begin{array}{l}0=\text { can't read or write/can read, but can write } \\
1=\text { Primary }(\leq 5 \text { years of schooling) } \\
2=\text { Junior high school }(6-10 \text { years of schooling }) \\
3=\text { Secondary or Higher Secondary (11-12 years of schooling) } \\
4=\text { Above High Secondary (more than } 12 \text { years of schooling) }\end{array}$ \\
\hline INCOME & Annual income (Taka) \\
\hline FARMSIZE & $\begin{array}{l}1=\text { less than } 0.5 \text { acres; } 2=0.5 \text { to less than } 1 \text { acre; } 3=1 \text { to less than } 1.5 \text { acres; } 4= \\
1.5 \text { to less than } 2.5 \text { acres; } 5=2.5 \text { to less than } 5 \text { acres; } 6=5 \text { to less than } 7.5 \text { acres; } \\
7=7.5 \text { to more than } 7.5 \text { acres }\end{array}$ \\
\hline OWNER & $=1$ if farmer owned the farm; $=0$ otherwise \\
\hline TRAIN & $=1$ if farmer received training on pesticide use and safe handling; $=0$ otherwise \\
\hline IPMD & $\begin{array}{l}=1 \text { if farmer received was currently practicing Integrated Pest Management; }=0 \\
\text { otherwise }\end{array}$ \\
\hline NPROTECT & $\begin{array}{c}=1 \text { if farmer used more than } 2 \text { protective measures; }=0 \text { otherwise } \\
\text { Other controls }\end{array}$ \\
\hline RICE & Proportion of area devoted to rice production (acres) \\
\hline POTATO & Proportion of area devoted to potato production (acres) \\
\hline BEAN & Proportion of area devoted to bean production (acres) \\
\hline EGGPLANT & Proportion of area devoted to eggplant production (acres) \\
\hline CABBAGE & Proportion of area devoted to cabbage production (acres) \\
\hline SUGARCANE & Proportion of area devoted to sugarcane production (acres) \\
\hline MANGO & Proportion of area devoted to mango production (acres) \\
\hline BOGRA & $=1$ if the farmer is located in the district of Bogra; $0=$ otherwise \\
\hline CHAPINAWABGANJ & $=1$ if the farmer is located in the district of Chapinawabanj; $0=$ otherwise \\
\hline CHITTAGONG & $=1$ if the farmer is located in the district of Chittagong; $0=$ otherwise \\
\hline COMILLA & $=1$ if the farmer is located in the district of Comilla; $0=$ otherwise \\
\hline JESSORE & $=1$ if the farmer is located in the district of Jessore; $0=$ otherwise \\
\hline KISHOREGANJ & $\begin{aligned}= & 1 \text { if the farmer is located in the district of Kishoreganj; } 0=\text { otherwise (Dropped in } \\
& \text { estimation) }\end{aligned}$ \\
\hline MUNSHIGANJ & $=1$ if the farmer is located in the district of Munshiganj; $0=$ otherwise \\
\hline NARSHINGDI & $=1$ if the farmer is located in the district of Narshingdi; $0=$ otherwise \\
\hline RAJSHAHI & $=1$ if the farmer is located in the district of Rajshahi; $0=$ otherwise \\
\hline RANGPUR & $=1$ if the farmer is located in the district of Tangpur; $0=$ otherwise \\
\hline MYMENSINGH & $=1$ if the farmer is located in the district of Mymensingh; $0=$ otherwise \\
\hline
\end{tabular}

